\title{
Un libro poco edificante. Historia de un niñito bueno. Historia de un niñito malo de Mark Twain
}

\author{
Marcela Carranza
}

¿Qué cuento más impropio para contarles a los niños! Usted acaba de minar los resultados de años de enseñanza cuidadosa.

Saki, "El cuentista”

\section{De lo inadecuado a lo correcto, de lo correcto a lo inadecuado}

Las historias que integran este libro de Mark Twain fueron publicadas originalmente en revistas distintas con cinco años de diferencia entre sí ${ }^{1}$. Primero apareció en la revista Californian (1865) "The Story of the Bad Little Boy That Led a Charmed Life"; luego en la revista Galaxy (1870) "The Story of the Good Little Boy Who Did Not Prosper". Ambos textos fueron reunidos en un mismo libro por Sketches, New \& Old en 1875 con ilustraciones de True Williams.

Lamentablemente carecemos de otros datos que pudieran sernos útiles acerca de las condiciones de producción y recepción de este texto en vida del autor; aunque su reedición ilustrada puede darnos indicios de una recepción exitosa por parte del público. Existen en la obra marcas que nos aproximan a un destinatario infantil, como las frecuentes apelaciones al lector por parte del narrador. Apelaciones que, por otra parte, derivan de la imitación burlesca de aquellos libritos de la escuela dominical a los que el texto de Twain hace alusión constante. Sin embargo, no podemos constatar si efectivamente este libro fue originalmente leído por los niños, ni cuál fue la reacción de los adultos en caso de que así fuera. Más de cien años después de su primera publicación, Historia de un niñito bueno. Historia de un niñito malo llega a los lectores infantiles a través de una colección de “clásicos” para niños (Twain 2005).

En la edición actual las imágenes cumplen un rol importante, tanto por el espacio que se les asigna como por el juego que establecen con el texto; también en su segunda edición de 1875 las ilustraciones adquirieron un rol protagónico, quizás a la manera de las ilustraciones de los libros pedagógicos parodiados por Twain. 

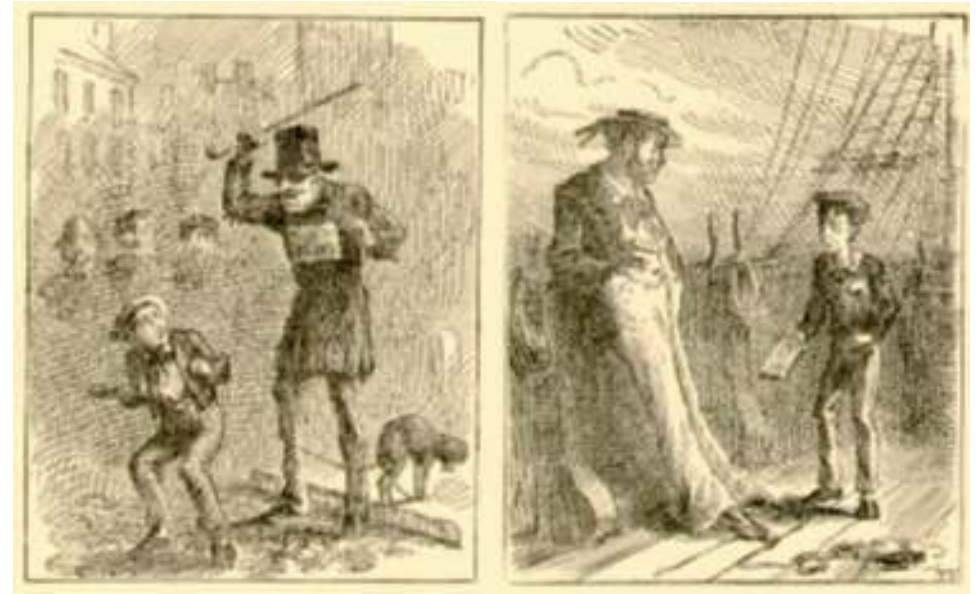

(C) Ilustraciones de True Williams para "The Story of the Good Little Boy" (1875).
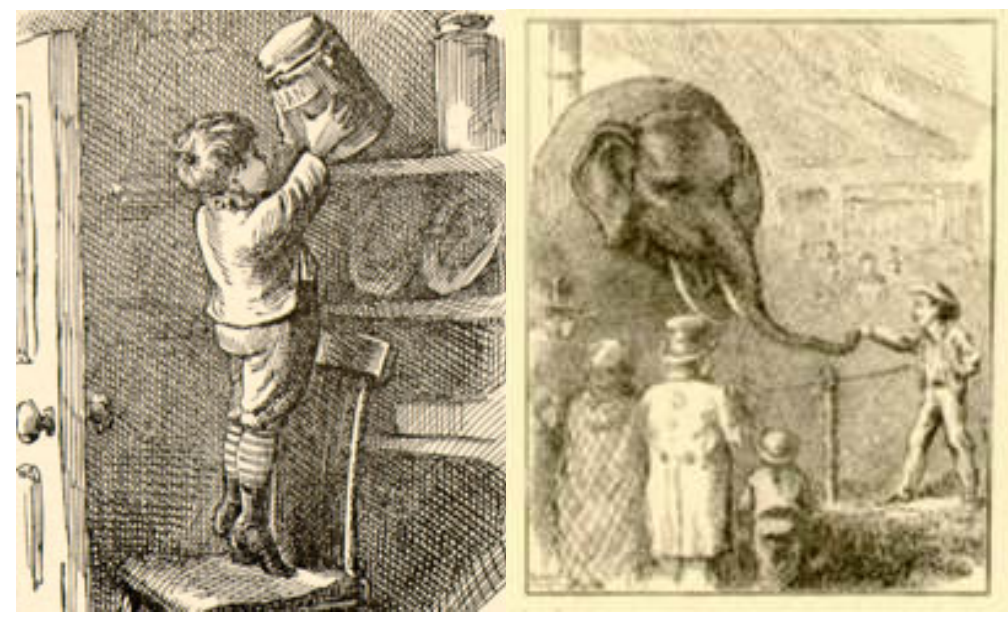

(C) Ilustraciones de True Williams para "The Story of the Bad Little Boy" (1875).

El texto de Mark Twain está construido sobre el andamiaje de un género pedagógico de la literatura infantil ya perimido, pero por lo visto aún vigente en época del autor: los libros de la escuela dominical. Este tipo de literatura surgió por parte de los pedagogos, y en particular de los religiosos, como un modo de contrarrestar la "mala influencia" de la literatura de cordel en los niños con menores recursos.

Desde fines del siglo XVI hasta entrado el siglo XIX tuvieron gran éxito entre las clases populares y los niños en particular unos libritos que, editados en forma de pliegos, eran distribuidos por buhoneros o vendedores ambulantes. Se trataba de una literatura sumamente heterogénea: cuentos de hadas, adaptación de novelas medievales, historias de santos, de criminales, noticias espantosas, relatos sobre toda clase de curiosidades, almanaques y calendarios, libros de medicina, de astrología, de profecías, de brujería, guías de viaje, tratados amorosos, diálogos dramáticos, obras burlescas, parodias de sermones o de tratados didácticos, adaptaciones populares de obras de la literatura “culta” como Los viajes de Gulliver, Robinson Crusoe y Gargantúa y 
Pantagruel. Esta literatura de cordel constituía una desigual y difícil competencia para la literatura infantil oficial. Era un material de lectura rechazado con vehemencia por pedagogos y pensadores por considerarlo nocivo, corrupto e inapropiado para la correcta formación de las mentes infantiles. Sin embargo, la innegable y enorme influencia sobre los niños de esta literatura significó la necesidad, por parte de los libros infantiles oficialmente aceptados, de modificar sus características formales e incluso temáticas, de acuerdo a los atractivos modelos de esta literatura de buhoneros, sin abandonar por ello su misión formadora de las nuevas generaciones. Así surgieron libros que, tomando elementos propios de la literatura de buhoneros con el objetivo de volverse atractivos para el público infantil, modificaron la función de estos elementos según el objetivo aleccionador que los justificaba ${ }^{2}$.

Los primeros libros de la escuela dominical actuaron como material de lectura escolar, sin embargo, a partir de la influencia “negativa” que la literatura de cordel ejercía entre los niños de la clases sociales bajas, según la visión de los educadores, los libros de la escuela dominical se transformaron en lectura también para el hogar, con el objetivo manifiesto de ofrecer a los niños de las clases bajas libros adecuados para su formación moral y religiosa.

Puede resultar interesante observar aquí cómo un género pedagógico surge de la necesidad de neutralizar las influencias en los lectores infantiles de una literatura considerada inadecuada para ellos por sus tutores y maestros. El género en cuestión se construye a partir del uso de elementos pertenecientes a aquella literatura que se quiere suprimir, pero con un deliberado desplazamiento en su función ${ }^{3}$. Podríamos hablar así de una imitación de estos libros “corruptores” y de su transformación en libros ejemplarizantes y formadores. Luego, Twain realiza la operación inversa. Nuevamente a través de la imitación, en su caso paródica, se distancia irónicamente de los libritos pedagógicos, desenmascara y relativiza el discurso moralizante adulto volviéndolo digno de absoluta desconfianza, incluso moral. Pero para ejemplificar este proceso pasemos al análisis del texto de Twain.

\section{La imitación paródica y el desenmascaramiento irónico}

Fiel al modelo de los libritos pedagógicos, el libro de Twain se construye a partir de dos historias “ejemplares”. Las hagiografías o historias de santos, así como los relatos de las hazañas de célebres criminales, tenían una larga tradición en la literatura popular. El 
relato ejemplarizante busca suscitar en los lectores determinadas acciones a partir de la imitación del modelo ofrecido por el texto. De allí que se busque en el lector la identificación con el protagonista y que éste a menudo asuma la edad del lector. Niños buenos que reciben su recompensa en ésta y en la otra vida; y niños malos castigados, arrepentidos y redimidos formaban parte de aquella literatura destinada a moldear moral y religiosamente las mentes y conductas infantiles.

El libro de Twain se divide en dos historias construidas paralelamente; ambas tienen idéntico inicio, presentan al personaje, narran un conjunto de buenas acciones/travesuras de cada uno de los protagonistas y desembocan abruptamente en el desenlace final. El paralelismo entre ambas historias es reforzado por la diagramación del libro y las ilustraciones.

"Había una vez un niñito bueno llamado Jacob Blivens”, es el inicio obligado de los relatos ejemplarizantes, pero ya en la segunda línea la voz narrativa se aparta de la norma habitual: "Siempre obedecía a sus papás sin importar cuán absurdas o irracionales fueran sus órdenes...” (Twain 2005: 9). Y unas líneas más abajo: “Nunca se iba de Pinta, incluso si su sano juicio le indicaba que era lo mejor que podía hacer”. (Ibid.).

Para este narrador los padres suelen dar órdenes absurdas e irracionales y la obediencia no siempre es juiciosa. Estamos lejos del narrador adulto/autoridad que predica a los niños las verdades del discurso oficial para la infancia. La figura del adulto y en particular de los padres suele ser cuidadosamente preservada en los relatos para niños $^{5}$. Este narrador, por el contrario, se aleja del discurso oficial adulto y se aproxima a la mirada infantil. Los otros niños no entienden a Jacob, y tampoco puede hacerlo el narrador para quien Jacob no es normal, es extraño. "Y era tan honesto que resultaba ridículo” (Ibid). Para este narrador, situado en el lugar de un niño común y corriente no es sensato, por ejemplo, el negarse a hacer travesuras: “No jugaba a las canicas los domingos, ni robaba nidos de pájaros, ni le daba monedas calientes a los monos de los organilleros; en fin, no parecía interesarse en ningún tipo de pasatiempo sensato” (Ibid.).

Luego de esta presentación del personaje, el narrador da una explicación al extraño comportamiento de Jacob: este “niñito bueno” leía todos los libros de la escuela dominical, y no sólo eso, creía en los niñitos buenos de los libros y quería ser uno de ellos. Su mayor anhelo era aparecer como protagonista en alguno de aquellos libros. 
En la primera parte se relata, al igual que en los libros admirados por el protagonista, la suma de escenas que dan cuenta del comportamiento ejemplar del héroe. Jacob reprende a los niños malos, ayuda a un anciano ciego, recoge a un perro abandonado, pretende alistarse como grumete en un navío, pero en cada una de estas escenas las cosas suceden a la inversa de lo acontecido en los libros. La historia de Jacob se construye como un mundo al revés de su modelo, lo que "invariablemente" sucedía en sus libros nunca sucedía en su vida: "Las mismas cosas por las que los niños en los libros eran recompensados, a él le resultaban puras calamidades” (Twain 2005: 18).

Jacob se queda estupefacto ante sus desventuras, pero también el narrador asume su punto de vista, y no puede comprender lo que pasa. La ironía es evidente: ¡Cómo puede ser que todas aquellas verdades de los libros no se cumplan para Jacob! Ni siquiera la dedicatoria de su maestro llega a conmover al capitán del navío en el que el niño quería embarcarse.

Definitivamente éste era, con mucho, el suceso más extraordinario que le había ocurrido en su vida. Los elogios de un maestro siempre despertaban los más tiernos sentimientos de los capitanes y despejaban el camino a toda clase de honores y recompensas para quien los recibía. (Twain 2005: 23)

El narrador asume el punto de vista ingenuo del protagonista y la máscara irónica ríe ante la "sagrada" palabra del maestro.

La muerte del protagonista es uno de los tantos tabúes respetados por los relatos infantiles, aunque formaba parte de los antiguos cuentos admonitorios de la tradición oral. A partir de la reconstrucción que este texto de Twain nos permite hacer de los relatos ejemplarizantes de la escuela dominical, vemos que los “niñitos buenos” solían tener una muerte solemne con últimas palabras y funeral incluido en el último capítulo. Del funeral, como de otras escenas, daban cuenta además del texto sendas ilustraciones, sobre las que el libro de Twain no escatima burlas:

[...] el niñito bueno siempre se moría en el último capítulo y había una ilustración del funeral, con todos sus parientes y sus compañeros de la escuela alrededor de la tumba, con pantalones demasiado zancones y gorros demasiado grandes, y todos llorando copiosamente en pañuelos tan grandes como una sábana. (Twain 2005:10)

La muerte, por lo tanto, no estaba vedada en este tipo de relatos, siempre y cuando cumpliera en él una función moralizadora y se guardara en ella cierta solemnidad de tinte melodramático ${ }^{6}$, según parece, esta última resaltada por la ilustración. 
A Jacob sin embargo esta parte de sus adoradas historias no le conformaba del todo, a él “le encantaba estar vivo” (Twain 2005: 13). Paradójicamente ésta es la única parte de su historia que coincide con sus lecturas favoritas, Jacob también morirá al final, sólo que su muerte no tendrá la solemnidad de sus libros de la escuela dominical.

En la historia de Jacob la inverosimilitud del melodrama y la solemnidad del momento final son reemplazadas por la hipérbole, el detalle macabro y el absurdo. La muerte de Jacob es una muerte prohibida para un relato infantil "adecuado", un desenlace de explosión y despedazamiento en el que el narrador se regodea con los detalles:

Y, en un instante, el niñito bueno salió disparado por el techo en dirección al sol con los pedazos de los quince perros colgando tras él como la cola de una cometa. No quedó rastro alguno del concejal o de la vieja fundidora sobre la faz de la Tierra, y en cuanto al joven Jacob Blivens, nunca tuvo oportunidad de decir sus últimas palabras después de lo mucho que le había costado prepararlas, a menos que se las dijera a los pájaros, porque aunque la mayor parte de su cuerpo cayó en la copa de un árbol del condado vecino, el resto quedó distribuido en cuatro pueblos cercanos, de modo que hubo que realizar cinco indagaciones para averiguar si estaba vivo o muerto ${ }^{7}$, y cómo había sucedido todo. Nunca se vio un niño tan hecho pedazos ${ }^{8}$ (Twain 2005: 24).

Hay algo del Quijote y de Madame Bovary en este pequeño que cree ciegamente en los niñitos buenos de los libros de la escuela dominical. Jacob es el "lector modelo" de aquellos libros, cuyo objetivo no era otro que el de moldear a los pequeños lectores a imagen y semejanza de los protagonistas. Como el Quijote, Jacob confunde realidad y ficción, cree que puede construir su vida de acuerdo a aquellas ficciones, y así le va. Pero a diferencia de lo sucedido con la literatura de caballerías, este gesto absurdo que pretende borrar los límites entre ficción y realidad, en los textos ejemplarizantes constituye parte de su objetivo pedagógico, de su razón de ser. Lo que Twain denuncia humorísticamente es la ridiculez de una retórica, de una ficción para niños que niega su carácter de ficción, y al hacerlo está a su vez negando la realidad del niño (y de la naturaleza humana en general), con el objetivo manifiesto de imponer esa ficción como modelo (absurdo e inverosímil) a alcanzar en la vida. Nadie, ni siquiera el narrador, cree en el "modelo de vida" propuesto por esta literatura, salvo Jacob que está loco o peca de la peor de las ingenuidades. Sin embargo el epílogo suma una nueva humorada en la voz del narrador, en éste se aclara al lector que el caso de Jacob ha sido "realmente excepcional”, “Todos los demás niños que siguieron tal ejemplo prosperaron, menos él” (Twain 2005: 26). 
El libro continúa en una segunda parte, cuyo inicio es idéntico al de la primera historia: "Había una vez un niñito malo llamado Jim [...] aunque, si te fijas, los niñitos malos casi siempre se llaman James en tus libros de la escuela dominical” (Twain 2005: 31).

La historia de Jim se abre con una apelación al niño lector de los libros de la escuela dominical, a partir de allí se construye como una constante negación del modelo parodiado: el de las historias de niños malos, castigados, arrepentidos y redimidos de aquellos libros. Jim no siente remordimiento, no escucha voces de la conciencia señalando el deber ser, no se arrodilla ni pide perdón; por el contrario hace lo que se le da la gana y no recibe castigo alguno ni de la autoridad celestial, ni de autoridades humanas.

En el segundo párrafo de la historia de Jim lo que se parodia a través de la inversión es la figura del adulto más "sagrada” de la literatura pedagógica (y en líneas generales de la literatura infantil), la figura de la madre:

Este niñito tampoco tenía una madre enferma; una madre enferma de tuberculosis y piadosa que con gusto se habría ido a la tumba para descansar en paz, de no ser por el gran amor que sentía por su hijo y la angustia que la invadía sólo de pensar que el mundo pudiera ser cruel y despiadado con él cuando ella le faltara. La mayoría de los niños malos de los libros de la escuela dominical se llaman James y tienen madres enfermas que les enseñan a rezar: Ángel de mi guarda, dulce compañía..., les cantan canciones de cuna con voz dulce y lastimera, les dan el beso de las buenas noches, se arrodillan junto a la cama y lloran. (Twain 2005: 31)

Pero no sólo la imagen de la madre frágil y cariñosa es blanco de ironías, sino toda una retórica melodramática que por lo visto estaba destinada en esta literatura a conmover el corazón del lector, con los fines pedagógicos previstos. La madre de Jim es una mujer fortachona, nada piadosa y para quien si su hijo "se rompía el cuello no sería una gran pérdida” (Twain 2005: 31). Esta madre antimodélica que, en lugar de besos de las buenas noches, le administraba nalgadas y sopapos a su vástago es reforzada por la ilustración. 


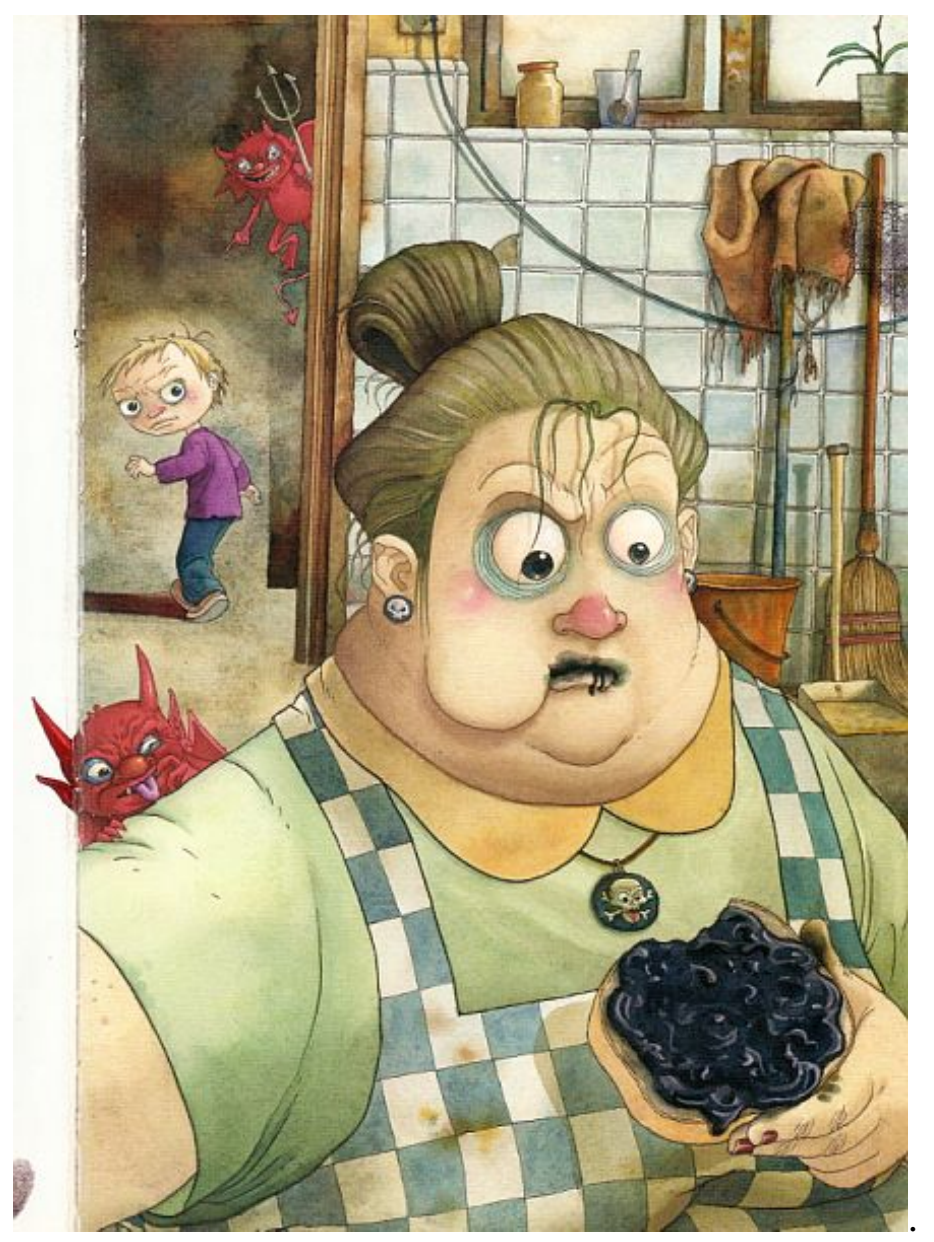

(C) Ilustración de Ricardo Peláez. Del libro Historia de un niñito bueno. Historia de un niñito malo, de Mark Twain. México: F.C.E, 2005.

Al igual que en la primera historia, el narrador manifiesta asombro frente al hecho de que las cosas no le sucedieran a Jim como en los libros de la escuela dominical. Las referencias a los libritos pedagógicos se vuelven insistentes y reiterativas, nada parece sucederles a estos personajes que no tenga su reflejo invertido en aquellos libros pedagógicos cuya lectura comparten narrador y narratario ${ }^{9}$. Así como la historia de Jacob se construye a partir de sus buenas acciones, la de Jim es la enumeración de sus travesuras; dos de las cuales - el robo de manzanas y el salir a velear en domingo - son reiteraciones de las escenas vividas por Jacob, desde la "vereda opuesta” respecto a la norma.

En la historia de Jim a menudo irrumpe el discurso del deber ser, no en boca del personaje, como en el caso de Jacob, sino como posibilidad de discurso que no se realiza. Así cuando el inocente es culpado, recibe el castigo inmerecido sin la intervención de ninguna fuerza superior y justiciera que pudiera venir en su ayuda:

[...] el pobre George bajó la mirada y se ruborizó como si se sintiera culpable, y el sufrido maestro lo culpó del robo, y cuando estaba a punto de darle un varazo 
en los hombros temblorosos, no apareció repentinamente ni se interpuso entre ellos un inverosímil juez de paz con peluca blanca para sentenciar solemnemente: “¡Soltad a este inocente niño, ahí tienen al verdadero cobarde culpable! Pasaba por la puerta de la escuela a la hora del recreo y, sin que nadie me viera, pude ver cómo se cometía el robo. (Twain 2005: 37)

Luego de enumerar todo aquello que no sucedió pero que habitualmente sucede en los libros, el narrador agrega:

No, eso habría pasado en los libros, pero no fue lo que le sucedió a Jim. Ningún viejo juez entrometido apareció para causar líos, así que George, el niño modelo, acabó castigado y Jim se alegró de ello porque, como podrás imaginarte, él odiaba a los niños obedientes. (Ibid)

Se ironiza sobre el discurso solemne y rimbombante del "deber ser" en boca del inverosímil e inexistente juez de paz, y al mismo tiempo se toma partido por el punto de vista del niño malo, cuando dicho juez es designado por el narrador como viejo entrometido. El punto de vista asumido es el del niño, y no precisamente el del niño bueno, a la vez que las apelaciones constantes al lector le hacen cómplice de esta mirada. El final de Jim, al igual que el de Jacob, también está atravesado por la hipérbole y el humor negro:

Y creció y se casó y tuvo muchos hijos, y una noche les rompió la crisma a todos con un hacha. Se hizo rico mediante toda clase de artimañas y engaños. Ahora es el bribón más cruel y despiadado del pueblo, es universalmente respetado y tiene un puesto en la Cámara Legislativa. (Twain 2005: 42)

En una misma frase el narrador enuncia tanto la extrema maldad del personaje como su exitosa posición social y política. La risa irónica se extiende entonces hacia cuestiones extratextuales: las reglas que habitualmente gobiernan las relaciones humanas y en particular las relaciones de poder. Estamos en este desenlace frente a la sátira política, se muestra un mundo funcionando según reglas inversas a la moral que rige el discurso oficial adulto dirigido a los niños ${ }^{10}$. A diferencia de la historia de Jacob, aquí el narrador no finaliza diciéndonos que Jim es un caso particular; lo es, pero tan sólo respecto a los libros de la escuela dominical.

Una de las características más sobresalientes de la narración en este libro es el uso de la reiteración. Se reitera hasta la saturación las alusiones a los libros de la escuela dominical, en forma de imitación por parte del personaje en la primera parte, y a través de la negación en la segunda parte. Ambas historias se construyen paralelamente en una especie de juego especular, como lo explicitan las ilustraciones de tapa y portada. A la reiteración deliberada de la narración, debe sumarse la reiteración que de los sentidos dados por el texto da cuenta la ilustración. En algunos casos sumando sentidos a los ya 
dados, como en la publicación que cierra la historia de Jim, donde a los éxitos del personaje se agrega el ser nombrado empresario del año.

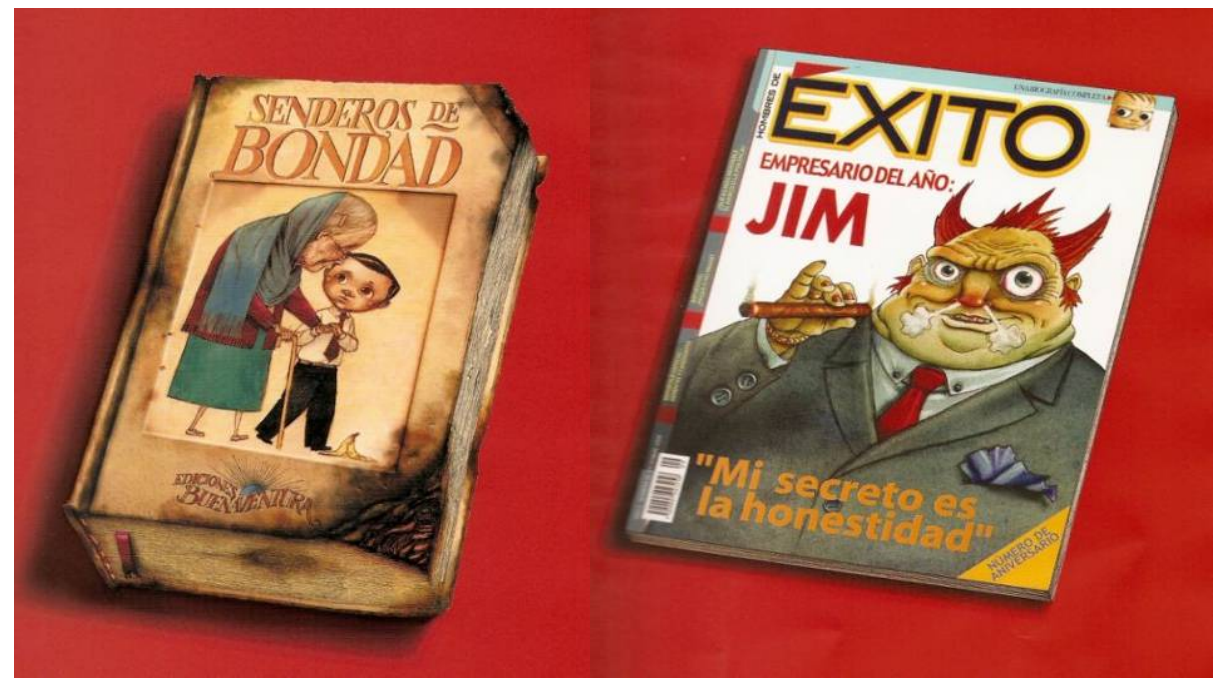

(C) Ilustraciones de Ricardo Peláez. Del libro Historia de un niñito bueno. Historia de un niñito malo, de Mark Twain. México: F.C.E, 2005.

Esta ilustración es paralela a la que cierra la historia de Jacob. El libro chamuscado de Ediciones Buenaventura agrega elementos macabros al catastrófico final del niño bueno. También los angelitos y diablos de las ilustraciones actúan como elementos repetitivos, en la medida que comparten las agonías y fechorías de los niños protagonistas. La reiteración resulta así uno de los elementos más sobresalientes del libro en su conjunto. Reiteración que persigue un efecto humorístico, en la medida en que imita burlescamente las insistencias y repeticiones hasta el hartazgo de la retórica moralizante, así como sus mecanismos de apelación al lector.

Se trata de la denuncia de los clichés ${ }^{11}$ que conforman estos textos cuya única función es la de adoctrinar a los niños en la moral vigente, fuera de cualquier objetivo artístico o literario. Así, todos los niños buenos mueren en el último capítulo diciendo sus últimas palabras, los niños malos se llaman James, y sus madres son sufridas y resignadas tuberculosas... De este modo la puesta en evidencia del cliché revela el carácter ficcional (inverosímil y absurdo) del modelo propuesto en los libros, como “modelo de vida".

La distancia irónica y la parodia tienen por blanco un género literario, pero la crítica no se detiene allí, este objeto literario no es otra cosa que el producto de un discurso adulto, de una manera de posicionarse frente al niño, y la crítica humorística se torna satírica. El texto de Twain no sólo se burla abiertamente de aquella literatura moralista de su época; su construcción se basa en la trasgresión de muchas normas que 
aún hoy regulan lo adecuado e inadecuado en la literatura para niños. Ante la palabra “seria” de la moral destinada a los niños, llena de convenciones, solidificada en estereotipos y clichés hallamos el lenguaje indirecto, paródico, irónico, satírico del libro de Twain. La máscara explícita de la ironía se distancia críticamente de ese lenguaje, lo desenmascara, muestra su ficción y su mentira, lo descubre sospechoso y absurdo, ajeno a la realidad que pretende corregir.

\title{
Una literatura que se piensa a sí misma
}

\author{
"iSi ya nos la sabemos de memoria!” \\ diréis. $Y$, sin embargo, de esta historia \\ tenéis una versión falsificada, \\ rosada, tonta, cursi, azucarada, \\ que alguien con la mollera un poco rancia \\ consideró mejor para la infancia... \\ Roald Dahl. "La Cenicienta”
}

Historia de un niñito bueno. Historia de un niñito malo es un texto del siglo XIX que conserva intacto su poder crítico. Los textos a los que hace referencia constantemente desde la burla paródica ya no existen, han caído en el olvido, como muchos otros textos y géneros didácticos; pero el libro de Twain continúa minando los límites actuales de lo “aceptable” en un libro infantil y generando resistencias entre los adultos mediadores.

Las historias de los niñitos de Twain ahondan en el fundamento lógico de la literatura ejemplarizante: la pretensión de borrar los límites entre ficción y realidad, literatura y vida $^{12}$. El libro de Twain parece decirnos: esos relatos destinados a enseñar a los niños a comportarse correctamente no sólo son estereotipados, ridículos, aburridos y pobres desde el punto de vista literario; implican una mentira, una falacia: la vida debe imitar a los libros.

Con Historia de un niñito bueno. Historia de un niñito malo nos situamos en la parodia, y también en la sátira, a la manera de un Jonathan Swift en "Su modesta proposición”13. Como Swift, Twain hace una denuncia moral, su texto habla del engaño y la mentira que los adultos inventamos para los niños a través de cierto tipo de literatura: les mostramos un mundo que no existe y pretendemos que vivan de acuerdo a él.

Detrás de las convenciones que reglan la producción, pero también la edición, la circulación y la lectura de los libros para niños, existen representaciones sociales e 
históricas acerca de la infancia, de la literatura destinada a ella, de los discursos que los adultos debemos dirigir a los niños, de cómo debemos relacionarnos con ellos. En otros términos, detrás de las restricciones (Cfr. Shavit, 1986) que condicionan los textos infantiles para ser aceptados dentro del sistema existe una ideología, un modo de comprender las relaciones entre los hombres, en particular entre los adultos y las nuevas generaciones. En su artículo “El enigma de la infancia” Larrosa señala:

La infancia es algo que nuestros saberes, nuestras prácticas y nuestras instituciones ya han capturado: algo que podemos explicar y nombrar, algo sobre lo que podemos intervenir. [...] No obstante, y al mismo tiempo, la infancia es lo otro: lo que, siempre más allá de cualquier intento de captura, inquieta la seguridad de nuestros saberes, cuestiona el poder de nuestras prácticas y abre un vacío en el que se abisma el edificio bien construido de nuestras instituciones de acogida. (2000: 166)

¿Cuál es el tipo de relación que a través de la literatura los adultos estamos dispuestos a establecer con esa otredad, en palabras de Larrosa: “absolutamente heterogénea respecto a nosotros y a nuestro mundo, absolutamente diferente” (2000:167)?

Podemos pensar esta relación: la de los adultos con los niños, como un encuentro entre dos “culturas” y entonces remitirnos a Bajtín:

Una cultura ajena se descubre más plena y profundamente sólo a los ojos de otra cultura; pero tampoco en toda su plenitud, porque llegarán otras culturas que verán y comprenderán aún más. Un sentido descubre sus honduras al encontrarse y toparse con otro sentido ajeno: entre ellos se establece una especie de diálogo, que supera el carácter cerrado y unilateral de ambos sentidos, de ambas culturas. [...] En un semejante encuentro dialógico de dos culturas, ellas dos no se funden ni se mezclan, sino que cada una conserva su unidad y su integridad abierta, pero las dos se enriquecen mutuamente. (2000: 159)

Históricamente los libros para niños han cumplido una función utilitaria. Su objetivo principal, al menos en los textos oficialmente aceptados, fue el de transmitir y favorecer determinados contenidos y conductas en sus lectores. Esto es muy fácil de observar en el pasado, pero quizá no tanto en el presente, ya que los contenidos y las representaciones del lector han cambiado acorde a los tiempos que corren. Sin embargo, no es exagerado decir que una gran mayoría de los libros infantiles que hoy se publican, continúan cumpliendo esta función de formar a los niños en la ideología vigente y moldear sus conductas de acuerdo a los proyectos adultos del momento.

Pero, al contrario de lo que podría suponerse, el libro de Twain no es un caso aislado de irreverencia en la literatura para niños. El humor macabro de Edward Gorey (2002, 2003, 2005), los clásicos parodiados de Roald Dahl, las historias de los hermanos Baudelaire de Lemony Snicket, "Un héroe” y otros prodigios de Ema Wolf, los 
monstruos de Tim Burton, los niñitos terribles de Saki, sin olvidar a clásicos infantiles del siglo XIX como "Max y Moritz” de Wilhelm Busch o las Alicias de Lewis Carroll, son algunos otros ejemplos de una literatura destinada a los niños que reflexiona sobre sí misma y su vínculo con la infancia.

Indagar en aquellos textos que escapan a la norma, que deliberadamente y de diversas formas transgreden y de este modo desenmascaran los límites que los adultos ponemos a las palabras dirigidas a los niños, puede ser un buen método para hacer visibles dichos límites y reflexionar sobre ellos.

\section{Referencias Bibliográficas}

Bajtín, M. (2000) La cultura. En Yo también soy (fragmentos sobre el otro), pp. 158163. México: Taurus.

Busch, W. (1982) Max y Moritz Una historia de chicos en siete travesuras. Trad. Víctor Canicio. Madrid: Alfaguara.

Carroll, L.; Tenniel, J. et al. (il.) (1998) Los libros de Alicia. La caza del Snack. Cartas. Fotografías. Trad. anotada de Eduardo Stilman. Prólogo de Jorge Luis Borges. Buenos Aires: Ediciones de la Flor, Best Ediciones.

Collodi, C.; Chiostri, C. (il.) (2002) Las aventuras de Pinocho. Trad. Guillermo Piro. Buenos Aires: Emecé.

Gorey, E. (2002) Amphigorey. Trad.O.Palmer Yañez. Madrid: Valdemar.

Gorey, E. (2003) Amphigorey también. Trad. O.Palmer Yañez. Madrid: Valdemar.

Gorey, E. (2005) Amphigorey además. Trad. O. Palmer Yañez. Madrid: Valdemar.

Larrosa, J. (2000) Elogio de la risa. O de cómo el pensamiento se pone, para bailar, un gorro de cascabeles. En Pedagogía Profana. Estudios sobre lenguaje, subjetividad, formación, pp. 149-164. Buenos Aires: Ediciones Novedades Educativas.

Montes, G. (1999) Una nuez que es y no es. En La frontera indómita, pp. 43-48. En torno a la construcción y defensa del espacio poético. México: FCE.

Mouralis, B. (1978) El campo de las contraliteraturas. En: Las contraliteraturas. Buenos Aires: El Ateneo.

Rest, J. (1991) Sátira. En Conceptos de literatura moderna, pp.141-142. Buenos Aires: Centro Editor de América Latina.

Saki (1997) El cuentista. En Cuentos de humor negro, pp.129-136. Trad.Carlos José Restrepo. Bogotá: Norma.

Shavit, Z. (1986) Poetics of Children's Literature. Athens and London: University of Georgia Press.

Stilman, E. (selección y notas) (1967) El humor negro. En El humor negro. Antología ilustrada. Buenos Aires: Brújula.

Swift, J. (1998) Una modesta proposición para evitar que los hijos de los pobres de Irlanda sean una carga para sus padres o su país, y para hacerlos útiles al público. En: Bretón, A. Antología del humor negro, pp. 21-26. Trad. Joaquín Jordá. Barcelona: Anagrama.

Twain, M.; Peláez, R. (il.) (2005) Historia de un niñito bueno, historia de un niñito malo. Trad. Una Pérez Ruiz. México: F.C.E. 
Twain, M.; Williams, T. (1875) The Story of the Good Little Boy, Virginia: University of Virginia Library.

Wolf, E. (2003) Libro de los prodigios. Buenos Aires: Norma.

Referencia de la autora:

Marcela Carranza es maestra, licenciada en Letras y máster en Libros y Literatura para Niños y Jóvenes (Universidad Autónoma de Barcelona, Banco del Libro de Venezuela y FGSR). Ha publicado artículos en revistas especializadas en literatura infantil y en educación. Participó como expositora en congresos de la especialidad. Actualmente coordina talleres en la escuela de capacitación docente de la Ciudad de Buenos Aires (CePA) y es profesora en el "Postítulo de Literatura Infantil y Juvenil" de la misma institución. Es profesora y coordina talleres de escritura en profesorados de formación docente de la ciudad de Buenos Aires. Colabora de forma permanente en "Imaginaria", publicación electrónica quincenal de literatura infantil y juvenil.

Email: marcecarranza@gmail.com

\footnotetext{
${ }^{1}$ Este artículo forma parte de un trabajo más extenso titulado: "El humor negro: una poética de la irreverencia en la literatura para niños.” Trabajo final para el Máster en libros y literatura para niños y jóvenes dictado por la Universidad Autónoma de Barcelona, Fundación Sánchez Ruipérez y Banco del Libro de Venezuela.

${ }^{2}$ Un ejemplo famoso de esta práctica según señala Shavit (1986: 166) es la del editor John Newbery (1713-1767), quien debe el enorme éxito comercial de su empresa a su habilidad para editar libros que combinaran elementos propios de la literatura popular que atraía a los niños con elementos morales y educativos acordes a la visión de padres y maestros. Sin embargo sus publicaciones tenían un destinatario limitado: los niños de la burguesía y clases superiores.

${ }^{3}$ Si bien esta "literatura de cordel" retomaba los valores oficiales, en general no es posible definirla conforme con la ortodoxia de las clases en el poder. Junto con obras de inspiración moral y cristiana, existía un buen número de textos transmisores de saberes y prácticas inaceptables para la Iglesia: astrología, profecía, magia blanca, brujería. También la moral oficial sufría duros golpes, como en los textos destinados a aconsejar en materia amorosa y manuales de correspondencia sobre seducción. “...la literatura de cordel trasmite y expresa una cultura diferente de la letrada simplemente porque habla de otra cosa y de otra manera" (Mouralis 1978: 21).

${ }^{4}$ La historia de Bertha en El cuentista de Saki (1997) comienza de igual modo. “Todos los cuentos eran terriblemente parecidos, sin importar quién los contara” (p. 132), señala el narrador utilizando el punto de vista de los niños. Como en el libro de Twain, la denuncia humorística frente a la literatura pedagógica se asienta en la repetición y el estereotipo, instrumentos útiles al fin didáctico, pero contraproducentes desde lo literario, y respecto al interés que despiertan en el lector. A poco de comenzar su historia, el narrador de Saki conecta las palabras "horriblemente” y "buena”, provocando el desvío de la narración hacia lo imprevisto. Los niños reaccionan favorablemente y el narrador señala: "Parecía haber en ello un dejo de verdad, ausente en los cuentos infantiles que la tía inventaba” (Saki 1997: 132) Aquí aparece otro elemento común al libro de Twain: el tema de la verdad ausente en los cuentos educativos.

${ }^{5}$ Dan cuenta de esto las adaptaciones de cuentos populares como Hansel y Gretel, donde la figura de la madre cruel es transformada en la madrastra, con el objetivo de preservar a la figura materna de sentidos negativos. Shavit (1986) da cuenta de esta restricción como parte de los límites sobre lo adecuado o inadecuado en un libro infantil, ejemplificándola con el caso de las modificaciones que sufre la figura original de Geppetto en las adaptaciones de Pinocho.

${ }^{6}$ En El cuentista de Saki el paseo por el parque de Bertha da lugar a una estética bucólica acorde al idealismo propio de un relato del "deber ser"; y en cortocircuito con ella introduce elementos poco habituales, grotescos y absurdos como la permutación de las ovejas por cerdos, y "los colibríes que al zumbar tocaban las tonadas más populares del momento" (Saki 1999: 134) El procedimiento consiste en utilizar un modelo convencional en los relatos infantiles educativos (melodrama, bucolismo) y desplazarlo hacia el ridículo y el absurdo.

${ }^{7}$ Los subrayados en las citas son nuestros. Al detalle macabro se suma el absurdo. Esta escena puede recordarnos el diálogo de los médicos cuando Pinocho es rescatado del árbol donde fue ahorcado (Cfr. Collodi 2002: 98).
} 


\footnotetext{
${ }^{8}$ Veamos el final del cuento del solterón en El cuentista de Saki: “[El lobo] Arrastró a Bertha afuera y se la devoró hasta el último bocado. Sólo quedaron los zapatos, pedacitos de ropa y las tres medallas ganadas por ser buena” (1997: 135). El desenlace del cuento relatado por el solterón a tres niños pequeños no sólo resulta impropio por macabro, sino que la niña, a la inversa de la más difundida Caperucita de los Grimm, es devorada no por su falta, sino por su obediencia: "Quien bien anda, mal acaba", sería el mensaje invertido del cuento del solterón, el mismo que podría aplicarse a la historia del sufrido Jacob Blivens. El humor macabro de la imagen final de los restos de la pobre Bertha, tan próximos a los catastróficos desenlaces de Der Struwwelpeter, suma impropiedad al relato. No sólo muere una niña buena por ser buena, sino que para colmo de males esto es motivo de burla. Ante este horrible desenlace, el público infantil imaginado por Saki se preocupa por el destino de los cerditos. La niña más pequeña acota: “-El cuento empezó mal [...] pero el final fue lindo" (Saki 1999: 135) El único reducto de moral queda a cargo del otro personaje adulto de la historia, la tía solitaria e impotente, única poseedora de sentido común dentro del grupo. La respuesta del solterón excluye todo argumento moral: él logró entretener a los niños durante diez minutos. Su literatura es impropia, pero efectiva.

${ }^{9}$ En esta segunda parte, la figura del lector de los libros de la escuela dominical se ha desplazado del protagonista al narratario. Jim, a diferencia de Jacob, no lee o no parece prestar atención a aquellos libros; el narrador apela entonces a los conocimientos que de ellos tendría "el lector".

${ }^{10}$ Según se define la sátira, ésta se aplica a cualquier "composición literaria que mediante el ingenio, la ironía o aun la invectiva ridiculice el comportamiento de individuos, la organización de sistemas políticos o ideológicos, la formulación de esquemas de pensamiento" y se propone "corregir los defectos humanos con auxilio de la risa que se suscita por el hecho de ponerlos en ridículo" (Rest 1991: 141). Su tradición se remonta a la antigüedad clásica, y tuvo "seguidores" entre los comediantes, entre ellos Aristófanes, y los filósofos Cínicos. Como figura humorística suele ser eliminada en las adaptaciones y textos infantiles obedientes a las restricciones que regulan convencionalmente lo "aceptable" en un relato para niños. Ver Shavit 1986: 145-150.

${ }^{11}$ La denuncia de los estereotipos artificiosos y repetitivos se extiende a las ilustraciones de este tipo de libros (Twain 2005: 10-13-34).

12 "El cuento es un universo nuevo, un artificio que alguien ha construido. [Allí] está explícitamente indicado que las palabras que lo forman nombran una ficción y no un referente real, que -deliberada, declaradamente- se está construyendo una ilusión, un mundo imaginario. En la ficción, la cuestión de si el discurso es verdadero o falso no es pertinente" (Montes 1999: 47).

${ }^{13}$ Swift, Jonathan "Una modesta proposición para evitar que los hijos de los pobres de Irlanda sean una carga para sus padres o su país, y para hacerlos útiles al público” (citado en Bretón 1998: 21-26).
} 